\title{
PARA QUE SERVE O SITE? UMA ANÁLISE DAS PÁGINAS DOS CANDIDATOS A GOVERNADOR E A SENADOR NO CEARÁ EM $2014^{12}$
}

\author{
Camila Mont'Alverne ${ }^{3}$ \\ Fernando Wisse Oliveira Silva ${ }^{4}$
}

\begin{abstract}
Resumo
A apropriação de recursos e ferramentas digitais da internet por parte das campanhas políticas traz, a cada pleito, novas configurações para a relação ente candidatos e eleitores. Este artigo propõe uma discussão sobre a utilização dos sites pessoais por candidatos políticos durante o período de campanha eleitoral. Particularmente, verifica-se como estão dispostas diferentes ferramentas nas páginas dos agentes e que tipo de ênfase os sites propõem para a comunicação política do candidato com os internautas. $\mathrm{O}$ corpus da pesquisa consiste em websites de campanha de seis candidatos (quatro para o pleito de Governador e dois para o de Senador, no estado do Ceará). A partir das categorias utilizadas por Schweitzer $(2005 ; 2011)$, a análise mostra que os candidatos dão maior ênfase a conteúdos informativos em suas páginas na web, deixando recursos de mobilização em segundo plano, enquanto ferramentas de participação são raras. Os websites continuam a ganhar novas ferramentas, mas a ênfase dos candidatos continua sendo a de utilizar tais plataformas como meios informativos e complementares para maximizar cotas de visibilidade e provocar um impacto positivo junto aos eleitores.
\end{abstract}

Palavras-chave: Campanha online; Eleições; Participação política; Ceará; Website.

\begin{abstract}
The usage of resources and digital tools by political campaigns brings, every new election, new shapes to the relationship between candidates and voters. This article proposes a discussion about the adoption of personal websites by political candidates during the electoral campaign. Particularly, we verify how these political agents dispose different tools in their sites and what kind of emphasis these pages propose to the political communication of candidate with users. The corpus consists in campaign websites of six candidates (four to State Governor and two for Senator by the state of Ceará). Using the categories created by Schweitzer $(2005 ; 2011)$, the analysis reveals that candidates emphasize informative content in their pages, leaving behind mobilization resources. Participation tools are rare. Websites keep gaining other tools, but the emphasis of candidates continues to be using these platforms as informative media and as an additional way to maximize their visibility and cause a positive impact to voters.
\end{abstract}

Keywords: Online campaign; Elections; Political participation; Ceará; Website.

\section{Resumen}

La apropiación de recursos y herramientas digitales de Internet por las campañas políticas trae, a cada elección, nuevos ajustes a la relación entre candidatos y electores. Este artículo propone una discusión acerca del uso de sitios personales por candidatos políticos durante el período de campaña electoral. Particularmente, se averigua como están organizadas herramientas distintas en las páginas de los agentes políticos y cual es el énfasis propuesto por los sitios para la comunicación política del candidato con los usuarios. El corpus de la investigación es formado por los sitios de campaña de seis candidatos (cuatro para Gobernador y dos para Senador por el estado de Ceará). Desde las categorías creadas por Schweitzer $(2005 ; 2011)$, el análisis revela que los candidatos enfatizan contenido informativo en sus sitios, dejando recursos de movilización en el fondo. Las herramientas

\footnotetext{
${ }^{1}$ DOI deste artigo: $10.5380 /$ recp.v6i1.39784.

2 Os autores são gratos ao parecerista anônimo; e a Isabele Mitozo e a Jamil Marques pelas considerações para o aprimoramento do artigo.

${ }^{3}$ Mestranda do Programa de Pós-Graduação em Comunicação (PPGCOM) da Universidade Federal do Ceará (UFC). Integrante do Grupo de Pesquisa em Política e Novas Tecnologias (PONTE). Bolsista Capes. E-mail: camilapessoa31@gmail.com

${ }_{4}^{4}$ Mestre em Comunicação pelo PPGCOM da UFC. Integrante do PONTE. E-mail: fernandowisse@gmail.com
} 
de participación son pocas. Los sitios continúan a ganar nuevas herramientas, pero el énfasis sigue siendo del uso de las plataformas como medios informativos y adicionales para aumentar la visibilidad y para crear un efecto positivo junto a los votantes.

Palabras-clave: Campaña en línea; Elecciones; Participación política; Ceará; Sitios.

\section{INTRODUÇÃO}

A internet, ao abrir canais de comunicação mais práticos e econômicos, tem modificado a forma pela qual as pessoas se relacionam socialmente. A Política, como parte integrante do conjunto de relações sociais, também sofre influência desta nova tecnologia. A adoção dos media digitais oferece, aos agentes políticos, maiores oportunidades de chegar aos cidadãos, ao mesmo tempo em que os expõe, obrigando-os a pensar estratégias de configuração de imagem pública em diferentes níveis.

Enquanto, no passado, os líderes políticos e seus estrategistas orientavam-se para cobrir e intervir na televisão, rádio e imprensa, agora estão envolvidos em uma considerável amplitude multidimensional de gerenciamento de impressões (BLUMLER, 2013, p.1 tradução própria ${ }^{5}$ ).

Os padrões de uso de websites de campanha eleitoral, por sua vez, têm passado por alterações no decorrer das evoluções tecnológicas e com o aumento das exigências dos cidadãos em relação aos candidatos. Não é mais suficiente oferecer apenas o endereço de email como ferramenta de interação ou utilizar a internet somente como modo mais rápido e econômico de disseminar o material de campanha (AGGIO, 2013; STROMER-GALLEY, 2013).

No caso brasileiro, somente na eleição de 2010, a legislação permitiu que as campanhas online fossem além de websites de candidatos e partidos políticos (AGGIO, 2013). Desse modo, pensa-se na utilização das redes sociais por parte desses agentes. A disponibilidade em se apropriar dessas ferramentas traz, além de novos elementos técnicos em relação às campanhas, novas cobranças por parte dos cidadãos.

A possibilidade de utilizar as redes sociais para campanha não faz, no entanto, com que os websites deixem de ser uma ferramenta adotada pelos candidatos. Prova disso é o levantamento de Braga et al. (2013), indicando que 69,2\% dos candidatos a governador e ao senado no Brasil em 2010 possuíam websites.

\footnotetext{
5 Todas as traduções deste artigo são de responsabilidade dos autores.
} 
Diferentemente das redes sociais, cujos recursos e potencialidades são pré-definidos, os websites são programados pelas próprias equipes de campanha de acordo com as necessidades que elas julgam ter. Em certa medida, as ferramentas oferecidas pelas páginas dos candidatos demonstram a disponibilidade deles em dialogar com os cidadãos, promover participação na campanha ou torná-la transparente.

\footnotetext{
Embora as mídias sociais tenham ganhado importância, websites são não só a "face pública" de uma organização (Lovejoy and Saxton, 2012), mas um dos instrumentos mais importantes para a comunicação externa de organizações políticas (Jentges et al., 2012) (NITSCHKE et al., 2014, p. 14).
}

Assim, o objetivo deste trabalho é identificar a ênfase dos websites dos candidatos a Governador e a Senador do Ceará nas eleições de 2014. Argumenta-se que, a partir de uma análise das páginas, é possível identificar qual a prioridade da estratégia de comunicação dos candidatos em seus sites. A comparação das páginas de candidatos a cargos diferentes também possibilita perceber se há diferenças nos padrões de uso das ferramentas de acordo com o cargo disputado e com as peculiaridades dos postulantes.

O artigo está organizado da seguinte forma: no próximo tópico é feita uma breve revisão de literatura sobre internet e eleições, a fim de delimitar como a temática vem sendo discutida por autores brasileiros e estrangeiros. Em seguida, discute-se o website pessoal do candidato como plataforma de comunicação política. Depois, são apresentadas as estratégias metodológicas e examinam-se os casos específicos da adoção de websites pelos candidatos a Governador e Senador do estado do Ceará nas eleições de 2014, junto da discussão dos achados. Por fim, apresentam-se as considerações finais.

\section{INTERNET E ELEIÇÕES}

A internet oferece uma série de possibilidades às campanhas políticas, como aumentar o alcance e a rapidez da distribuição do material de campanha, diminuir a dependência do Horário Gratuito de Propaganda Eleitoral (HGPE), divulgar informações que não teriam visibilidade nos media tradicionais e abrir canais de participação aos cidadãos (ALDÉ; MARQUES, 2015; GIBSON et al., 2003; GULATI; WILLIAMS, 2007; MARQUES; SAMPAIO; AGGIO, 2013). A depender da cultura política de cada sociedade, a utilização da internet para fins políticos tem o potencial de agregar visibilidade e de servir como plataforma de comunicação entre agentes do campo político e sociedade.

"O nascimento da internet e de outras tecnologias digitais amplificou a importância das novas formas de visibilidade criadas pela mídia e, ao mesmo tempo, tornou-as mais 
complexas" (THOMPSON, 2008, p.23). Isto significa dizer que, com a internet, há uma pluralização dos atores que constroem a esfera de visibilidade pública, porque uma maior quantidade de falas se torna publicamente acessível (SANTOS, 2012). Além da dispensa do compartilhamento de espaço e tempo entre quem publica uma informação e quem acessa, os media digitais permitem disponibilizar permanentemente a informação.

A internet, enquanto modalidade de comunicação do campo midiático, constitui modelos e processos específicos de utilização e interação. Nesse sentido, também possibilita uma modalidade peculiar de visibilidade, na qual a disponibilização de conteúdo pode ser realizada tanto por instituições como por indivíduos. A utilização de recursos digitais, a exemplo de sites pessoais, redes sociais e sites de compartilhamento de vídeo e imagens, traz novas configurações para a relação entre esfera política e sociedade (AGGIO, 2011). Boa parte dos trabalhos desenvolvidos sobre essa temática abrange, especialmente, a utilização do sites e perfis em redes sociais nas campanhas políticas majoritárias. Esses trabalhos analisam os padrões de uso por parte do candidato e procuram dimensionar as estratégias de comunicação utilizadas e a interação entre candidatos e eleitores (AGGIO, 2011; 2013; ALDÉ; MARQUES, 2015; CERVI; MASSUCHIN, 2011; DRUCKMAN et al., 2009; MARQUES et al., 2013; ROSSETTO et al., 2012).

Em tempos atuais, verifica-se uma transposição das estratégias do campo da comunicação de massa para as plataformas de comunicação digital, como a criação de sites de partidos para recrutamento de militantes e arrecadação de recursos (MARQUES et al., 2013). A televisão ainda recebe maior atenção dos agentes políticos ${ }^{6}$, mas a exploração de novos media, como a Internet, tem crescido e mostrado que seu potencial comunicacional merece ser considerado como uma alternativa barata, de alto grau de difusão e sem limitações de tempo.

No processo eleitoral, existe uma disposição muito mais ampla por parte dos agentes políticos de se mostrarem abertos à interferência por parte da esfera civil. A internet acaba conformando uma alternativa à qual os candidatos recorrem na intenção de estabelecer um contato direto com o eleitorado, evitando a intermediação dos media tradicionais, que adotam

\footnotetext{
${ }^{6}$ Segundo estudo da Associação dos Peritos Criminais Federais (APCF), os gastos com programas de TV, por candidatos a governador e prefeito nas eleições e 2010 e 2012 em todo o país, chegam a R $\$ 84$ milhões, ficando atrás apenas das despesas com pessoal ou serviço de terceiros. Disponível em: http:/ / congressoemfoco.uol.com.br/noticias/programa-de-tv-e-o-segundo-maior-gasto-nas-campanhas/ Acesso em 25 ago. 2014.
} 
critérios próprios de noticiabilidade e de oferta de visibilidade (MARQUES et al., 2013). Atualmente, o impacto da internet nos media e na sociedade é visível, tornando-se um vasto campo de pesquisa sobre diversos aspectos como comportamento, linguagem, dentre outros.

Fazer uso das ferramentas digitais tornou-se essencial para agentes políticos, partidos e instituições que querem ter visibilidade pública e manter uma interação com o eleitorado, por exemplo. Não adianta mais oferecer apenas o e-mail como forma de contato, é preciso um site atualizado, perfis em redes sociais, assessoria de imprensa especializada, media-training, a utilização de diferentes mídias, ou eles correm o risco de serem tachados de ultrapassados ou de serem acusados de avessos às contribuições (e críticas) que muitos usuários se dispõem a oferecer (MARQUES; SAMPAIO, 2011; MARQUES et al., 2013).

Nas eleições presidenciais norte-americanas de 2004, por exemplo, o universo dos blogs foi um fenômeno em foco, com Howard Dean, candidato nas prévias pelo partido Democrata. Pelos blogs, ele abriu vias diretas no contato com o eleitorado e arrecadou cerca de 15 milhões de dólares para apoio à campanha. Porém, perdeu a nomeação para John Kerry. Na corrida à Casa Branca, George W. Bush e John Kerry também apostaram neste novo dispositivo, criando diários de campanha na blogosfera (MAAREK, 2011).

Em 2008, a internet foi, novamente, um elemento importante na manobra de outro candidato Democrata, Barack Obama, que utilizou quase todas as aplicações online disponíveis no momento (AGGIO, 2013) ${ }^{7}$, além de ter arrecadado recursos financeiros pelas doações online (VACCARI, 2013).

No Brasil, as novas possibilidades de relacionamento nas eleições presidenciais de 2010 com o uso da internet ganharam mais espaço a partir da Lei n ${ }^{\circ}$ 12.034/09, que liberou, por exemplo, o uso de blogs, sites e redes sociais, em geral, como Orkut, Twitter, Facebook e YouTube, permitindo aos candidatos o uso dessas páginas sem rigorosas restrições, durante o período eleitoral. Antes das eleições de 2010, a legislação eleitoral restringia o uso de ferramentas online para interação e participação do eleitor com o candidato, havendo uma série de limitações e punições (AGGIO, 2013).

\footnotetext{
7 Para autor, existem três estágios no uso da internet pelos políticos: (1) “pré-web", que concentra o uso da internet no envio de mensagens eletrônicas e e-mails, sem um uso interativo dos websites por parte dos políticos; (2) um estágio "Web", que tem como plataforma básica de contato dos políticos com o público em geral os websites pessoais, basicamente reproduzindo os conteúdos das mídias tradicionais; (3) e uma terceira etapa iniciada com a campanha presidencial de Barack Obama, qualificada de "pós-web", na qual os websites passam a ser apenas uma ferramenta virtual entre outras empregadas pelos políticos, cumprindo a função de ser um distribuidor de conteúdo a ser reproduzido nas mídias sociais (AGGIO, 2013).
} 
Philippe J. Maarek (2011) afirma que o uso da Internet em campanhas políticas ganha novas configurações a cada período eleitoral. Vê-se um uso cada vez mais frequente de ferramentas de interação por parte dos políticos - sites pessoais, blogs e perfis em redes sociais, por exemplo.

Durante a campanha, os políticos e os seus apoiadores também travam uma luta interna a fim de gerenciar e de ser mais "visível" na Internet que os seus adversários usando truques conhecidos em e- Marketing, entre os quais:

- Compra de palavras-chave bem escolhidas nos motores de busca - principalmente, o Google, a fim de redirecionar internautas para os sites da campanha;

- Simular sites ou internautas a fim de divulgar mensagens a favor do candidato para usuários que não visitam sites de políticos.

- Multiplicar blogs "amigos", a fim de aumentar o burburinho da Internet, permitindo não só que mais categorias de internautas possam ser alcançadas, mas também para enganar os motores de busca. Uma vez cruzado o "gosto artificial" desses blogs, a classificação deles melhora quando os internautas realizam uma pesquisa; na verdade, muitos desses blogs são geridos diretamente pela equipe de campanha ou por militantes do partido que pediu para ajudar abrindo seus próprios blogs;

- Comprar anúncios em outros sites "não-políticos", até comerciais, em países nos quais a prática é permitida, alcançando excelente segmentação, se os locais e os sites são bem escolhidos;

- Usar sites de redes sociais para disseminar a comunicação e manter o político visível na Rede.

Aumentando a cota de visibilidade, as vantagens oferecidas pela internet proporcionam um ambiente fértil para a comunicação política. Porém, a utilização dessas ferramentas requer cautela extra no momento da publicação de conteúdo, a fim de evitar gafes perante o público-alvo.

O uso da Internet também possui o potencial de equilibrar o jogo da comunicação política entre os partidos, em face do baixo custo dos sites em comparação com outras mídias tradicionais e da sua possibilidade de veiculação de conteúdo multimídia. De acordo com esta perspectiva, denominada hipótese da "equalização", uma vez que todos podem obter

\footnotetext{
8 "Gosto artificial" se refere ao número de acessos a uma página ou o número de "likes".
} 
espaço na rede mundial, os pequenos partidos são comparativamente mais beneficiados do que os grandes. A ela se opõe a hipótese da "normalização", segundo a qual os grandes partidos têm acesso a melhores profissionais e maiores recursos em relações aos partidos menores, o que limitaria o poder dos sites de atuar como fator de equilíbrio entre os partidos (STRANDBERG, 2008). Braga et al. (2011), em estudo sobre o caso brasileiro, dizem que não se verifica estritamente a hipótese da normalização.

\section{SITES PESSOAIS COMO PLATAFORMA DE COMUNICAÇÃO POLÍTICA}

A adoção de sites pessoais dos candidatos em campanhas políticas traz à tona a "interatividade" como um recurso a ser aplicado na comunicação política online. Richard Davis (1999) afirma que a interação online expõe o discurso da campanha política a uma condição vulnerável, pois há o receio de perder o controle e tornar as páginas vulneráveis a conteúdos "impróprios", além de demandar um gasto excessivo de tempo para responder mensagens e cobranças para a constante atualização de conteúdos.

Logo, o autor conclui que os candidatos utilizam a internet como meio de promover suas candidaturas e maximizar suas cotas de visibilidade, mais que como um fórum para debater com os cidadãos (DAVIS, 1999). Pensamento semelhante têm Lilleker et al. (2010, p. 107). "Em uma era de campanha permanente, nós sugerimos que o propósito principal da comunicação é ajudar a ganhar eleições ou adquirir recursos (dinheiro, apoiadores) que irão ser usados para angariar votos".

Porém, nota-se que alguns agentes políticos estão utilizando sites pessoais para além de conteúdos que seriam apenas a transposição de material off-line para online. Em alguns casos, há adoção de ferramentas participativas e de integração, possibilitando uma aproximação entre os candidatos e o eleitorado (GOMES, 2008; AGGIO, 2013; WILLIAMS; TRAMMELL, 2005). O website torna-se um ambiente sem restrições de tempo ou espaço com alto potencial para a discussão de propostas.

É possível considerar os sites também do ponto de vista da sua potencialidade para promover a democratização política (seja através de uma participação mais direta dos membros comuns e eleitores nos debates de programas de governo, seja através de uma equalização das condições de comunicação política entre os candidatos), ou de um ângulo estratégico, como instrumentos que permitiriam ao candidato incrementar a sua 
comunicação com os eleitores e até mesmo para atender às questões organizacionais dos partidos no que tange os objetivos das agremiações políticas (NITSCHKE et al., 2014).

Vale ressaltar que as possibilidades oferecidas pela ferramenta não asseguram a realização do fenômeno. Não necessariamente o potencial de uma tecnologia será apropriado pelos usuários da maneira prevista pelos seus criadores e divulgadores. Segundo Römmele (2003), as formas de uso das ferramentas digitais dependem dos interesses dos agentes e do momento político, o que nos dá diferentes graus de interação promovidos por diversos partidos em seus websites. Conforme afirma Pipa Norris (2001), a disponibilidade técnica dos meios digitais é apenas parte do que explica os modos através dos quais a internet vem sendo utilizada na política. Para a autora, outros fatores, como gênero, escolaridade e renda, influenciam fortemente o padrão de relacionamento dos cidadãos e atores políticos com os media digitais.

\section{ESTRATÉGIAS METODOLÓGICAS}

O corpus analisado é composto por seis sites dos candidatos a Governador e ao Senado pelo Ceará em 2014. As páginas foram visitadas no dia 21 de agosto, dois dias após o início do HGPE (Horário Gratuito de Propaganda Eleitoral).

Esperava-se que, caso a utilização das ferramentas digitais estivesse incipiente porque a propaganda no rádio e na TV ainda não havia começado (período anterior ao analisado aqui), tal quadro seria alterado com o início desta nova fase da campanha, tornando o intervalo mais representativo dos padrões de uso dos websites por parte dos candidatos. Além disso, neste momento da campanha, parte importante das estratégias que serão adotadas até o dia da eleição já estão definidas, de modo que não são esperadas grandes alterações na estrutura dos websites. Para assegurar se houve alterações significativas durante o período eleitoral, os sites foram visitados novamente no dia 2 de outubro, três dias antes da realização do primeiro turno das eleições.

A busca pelos sites dos candidatos foi realizada a partir do Google e das páginas nas redes sociais oficiais deles, pois os postulantes não indicavam o endereço das páginas nos registros no Tribunal Superior Eleitoral. Na tabela abaixo, apresentam-se os candidatos que compõem o corpus e seus respectivos websites. Foram analisados os sites de todos os candidatos a Governador e ao Senado pelo estado que possuíam páginas de campanha. 
Tabela 1 - Candidatos a Governador do Ceará e seus sites

\begin{tabular}{l||l}
\hline \hline Candidato (a) & Site \\
\hline Ailton Lopes (PSOL) & http://ailtonlopes50.com.br/ \\
\hline Camilo Santana (PT) & http://camilogovernador.com.br/ \\
\hline Eliane Novais (PSB) & http://www.eliane40.com.br/ \\
\hline Eunício Oliveira (PMDB) & http://www.eunicio.com.br/ \\
\hline \hline
\end{tabular}

Fonte: autores.

Tabela 2 - Candidatos a Senador do Ceará e seus sites

\begin{tabular}{l|l}
\hline \hline Candidato (a) & Site \\
\hline Mauro Filho (PROS) & http://mauro900senador.com.br/ \\
\hline Geovana Cartaxo (PSB) & http://geovana400.com.br/ \\
\hline Tasso Jereissti (PSDB) & http://tasso.com.vc/ \\
\hline Raquel Dias (PSTU) & Sem site \\
\hline \hline
\end{tabular}

Fonte: autores.

A fim de identificar a ênfase dos websites, foram analisadas as ferramentas oferecidas neles a partir das categorias estabelecidas por Schweitzer $(2005$; 2011) para examinar as páginas de partidos políticos alemães. Foram feitas adaptações ao contexto das campanhas de 2014 no Brasil, a partir de visita prévia aos websites dos candidatos. As categorias adotadas são:

- Informação: “(...) recursos relacionados com a apresentação e distribuição de informações sobre partidos, agentes políticos e eventos" (SCHWEITZER, 2005, p. 333).

- Mobilização: Ferramentas destinadas a fomentar o apoio dos cidadãos ao candidato ou ao partido.

- Integração: Coordenação entre as diversas ferramentas de comunicação digital do candidato e do partido.

- Participação: “(...) opções que facilitam uma relação interativa” (SCHWEITZER, 2011, p. 315) entre os cidadãos e os candidatos. Também são consideradas de participação ferramentas que possibilitam apresentar propostas ao plano de governo ou debatê-lo. 
As categorias são eixos a partir dos quais foram analisadas ferramentas disponíveis nos websites. Com a identificação da presença ou ausência delas, foi calculado o peso de cada categoria nas páginas dos candidatos. A definição das ferramentas observadas conta, além de visitas prévias aos sites, com as contribuições das análises empreendidas por Gibson e Ward (2000), por Gulati e Williams (2007), por Vaccari (2013) e por Nitchske et al. (2014). Os trabalhos, por terem sido elaborados em contextos diferenciados entre si, trazem elementos distintos e acabam atualizando-se, na medida em que dialogam e trazem questões não abordadas pelos textos anteriores.

Em cada categoria, foi observada a presença ou ausência dos seguintes elementos:

\section{INFORMAÇÃO}

Informações gerais sobre o sistema político

Informações sobre o partido

Informações sobre o candidato

Informações sobre o vice ou suplentes

Informações sobre o programa de governo

Documentos oficiais

Notícias sobre a campanha

Agenda

Releases (ou a possibilidade de se cadastrar para recebê-los

Arquivo de notícias

Arquivo de fotos

Arquivo de vídeos

Contato

Serviço de SMS ou Whatsapp

Prestação de contas de campanha

\section{MOBILIZAÇÃO}

Download de material de campanha

Aplicativos do candidato para download

Possibilidade de o eleitor se cadastrar no site para receber atualizações 


\begin{abstract}
Pedido de contribuição financeira para a campanha
Possibilidade de o eleitor doar online

Possibilidade de o eleitor enviar vídeos, fotos ou mensagens de apoio ao candidato

Possibilidade de compartilhar o material do site em redes sociais

Eleitor pode personalizar avatar das redes sociais com botton do candidato

Possibilidade de se cadastrar para ser voluntário na campanha

Menções a outros candidatos pelo partido ou coligação
\end{abstract}

\title{
INTEGRAÇÃO
}

Site ligado às redes sociais do candidato

Links para site ou redes sociais do candidato à Presidência pelo partido ou coligação

Links para sites ou redes sociais de outros candidatos pelo partido ou coligação

\section{PARTICIPAÇÃO}

E-mail/fale conosco

Possibilidade de comentar no site

Acervo dos comentários

Enquetes

Fóruns/espaço para discussão do plano de governo

Acervo dos fóruns ou da discussão do plano de governo

Possibilidade de comentar as ideias dos outros usuários

Jogos

Espaço ara conversa em tempo real com os usuários via vídeo ou texto

Acervo das conversas em tempo real com os usuários

Os autores codificaram os sites em conjunto, a fim de discutirem sobre as discordâncias, encontrar fragilidades na categorização proposta e torná-la mais confiável. Esta estratégia também foi adotada por Marques e Mont'Alverne (2014), em artigo sobre o conteúdo de tweets de candidatos a vereador em Fortaleza.

A presença de uma ferramenta adicionava um ponto à categoria analisada. A ausência, não acrescentava nenhum. Após a codificação, gerou-se a porcentagem da presença dos elementos em cada eixo, a fim de identificar a ênfase da estratégia de comunicação de cada website. Em anexo, estão print-screens das páginas dos candidatos, feitos no dia da análise. 


\section{ANÁLISE E DISCUSSÃO DOS RESULTADOS}

Gráfico 1 - Candidatos e a ênfase de cada site (EM PORCENTAGEM) - AGOSTO DE 2014

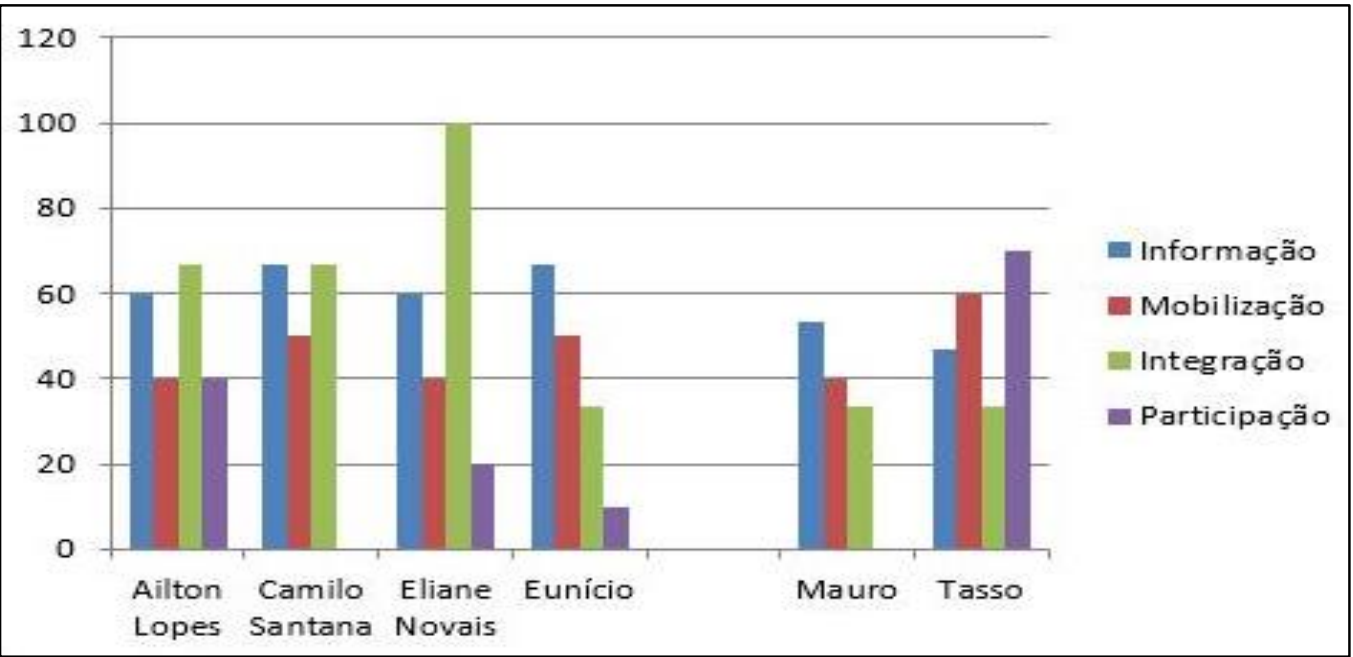

Fonte: autores.

Os dados do Gráfico 1 chamam a atenção para a alta taxa da ênfase em Informação e Integração dos sites dos candidatos ao Governo do Ceará. Camilo Santana (PT) e Eunício Oliveira (PMDB) têm como ênfases primordiais as ferramentas de Informação.

Outro ponto explorado pelo site de Santana são ferramentas de Integração. A página está ligada tanto às redes sociais dele quanto ao site do candidato ao Senado pela coligação, Mauro Filho (PROS). Já o website do candidato do PMDB liga-se apenas às redes sociais dele.

Nos sites de Ailton Lopes (PSOL) e Eliane Novais (PSB), a ênfase está em Integração. A página da candidata do PSB atende a todos os requisitos da categoria. A do postulante do PSOL, por sua vez, só não apresenta links para redes sociais ou sites de outros candidatos do partido ou da coligação.

Outro eixo privilegiado nos websites dos dois é o de Informação. O site de Ailton, inclusive, apresenta um diferencial em relação aos outros candidatos, pois disponibiliza a prestação de contas da campanha.

Em relação às outras categorias, de forma geral, os candidatos a Governador do Estado só utilizam ferramentas de mobilização de forma mais recorrente que aquelas de participação. Neste sentido, é notável o fato de Ailton Lopes ser o único que não disponibilizou o material de campanha para download e o site de Eliane Novais ser o único 
a não permitir o compartilhamento direto de seu material nas redes sociais, pois não dispõe dos atalhos necessários para isso. O site de Ailton é, ainda, o único que pede doações para os usuários, mas não é possível fazê-las online.

Os sites de Eunício e Camilo apresentam padrões semelhantes de adoção de ferramentas de mobilização. Em ambos, há a possibilidade de fazer download do material de campanha, de o eleitor se cadastrar para receber atualizações, de compartilhar o material em redes sociais e menções a outros candidatos do partido ou da coligação. Camilo disponibiliza, também, um aplicativo para download, enquanto Eunício oferece a possibilidade de o eleitor enviar vídeos, fotos ou mensagens de apoio à candidatura, ferramenta também explorada por Eliane, embora de modo mais tímido. A candidata do PSB disponibiliza um mural no qual os usuários podem escrever mensagens. A segunda visita ao site dos candidatos revelou que Eunício também disponibilizou um aplicativo para os cidadãos, enquanto Eliane passa a permitir o compartilhamento de seu material nas redes sociais. A página de Camilo não sofreu alterações.

Gráfico 2 - Candidatos e a ênfase de cada site (EM PORCENTAGEM) - OUTUBRO DE 2014

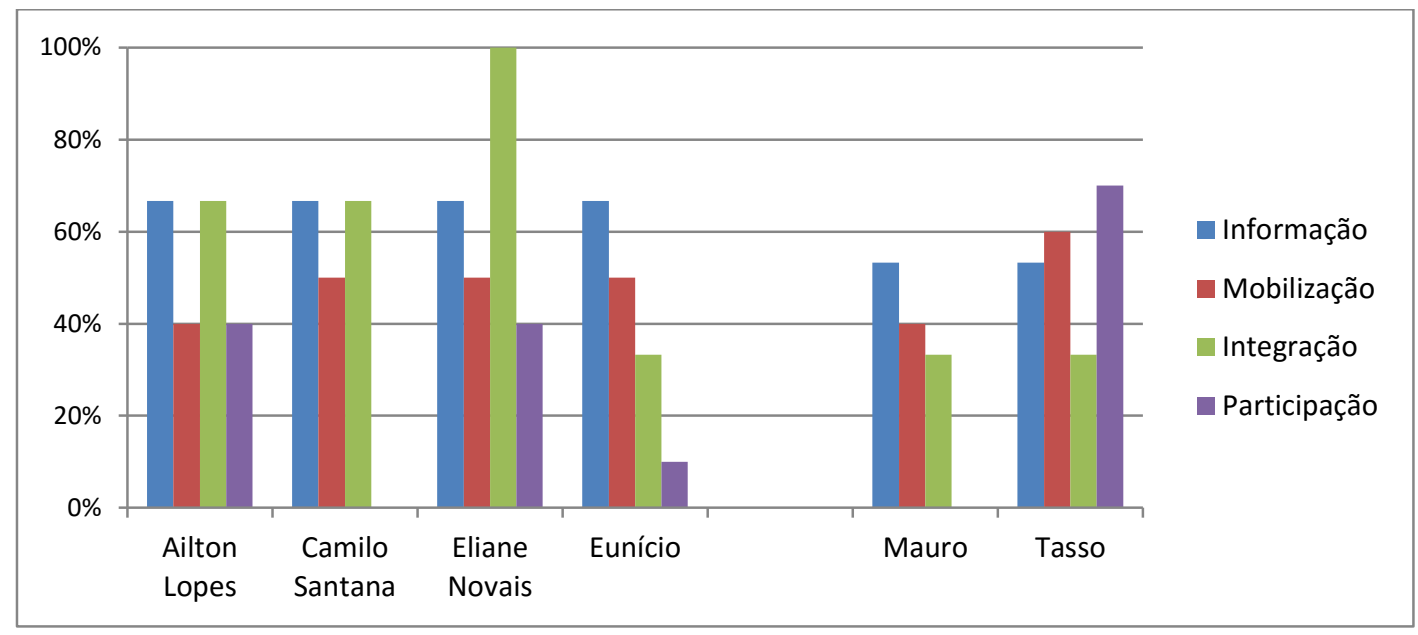

Fonte: autores.

O site de Eunício se destaca quanto à navegabilidade e acessibilidade, embora estas categorias não tenham sido analisadas pelo trabalho. Deixa-se apenas a nota de que, dentre as páginas analisadas, apenas o candidato do PMDB apresenta ferramentas que auxiliam pessoas que têm dificuldades de visualização na tela do computador. O usuário pode mudar o contraste de claro para escuro, alterando a combinação de cores, possibilitando que pessoas com baixa visão possam visualizar o conteúdo, além de permitir alterar o tamanho da fonte. 
As ferramentas de participação são as menos utilizadas pelos candidatos a Governador, de forma geral. Chama atenção, em especial, o site de Camilo Santana, que não oferece nem as formas mais básicas de participação, como um Fale Conosco ou a possibilidade de comentar o material da página. Mais que isso: nenhum dos postulantes ao Governo do Estado ofertava fóruns ou espaços para discussão dos programas de governo. Eunício destina um espaço para o cidadão enviar sugestões ao plano de governo, mas este é o mesmo do Fale Conosco, no qual não se sabe o destino das mensagens.

Os sites dos candidatos ao Senado diferem em suas ênfases. O de Mauro Filho (PROS), cuja estrutura é semelhante à da página de Camilo, enfatiza ferramentas de Informação. O de Tasso (PSDB) prioriza as possibilidades de Participação. A segunda visita ao site do último constatou a presença de uma ferramenta que permite aos cidadãos enviarem propostas ao candidato e verem as que foram enviadas pelos outros. Tasso, porém, não divulgava suas ideias. Não é possível falar, portanto, em uma ingerência efetiva por parte dos cidadãos nas propostas do candidato. Além de não as apresentar, o site do candidato do PSDB também não oferece espaços específicos para debatê-las ou criticá-las. Jereissati se utiliza, no entanto, de ferramentas desconsideradas pelos outros candidatos, como jogos e conversas em tempo real com os usuários.

É curioso observar que, mesmo com os sites possuindo, em maior ou menor grau, forte caráter informativo, nenhum deles traz informações gerais sobre o sistema político ou sobre o partido. Até informações sobre os candidatos a vice ou a suplentes são raras, estando presentes apenas nas páginas de Camilo e de Eliane.

A página de Tasso, por sua vez, é a mais eficiente em se apropriar de estratégias de Mobilização dos eleitores. Ela é a única que permite o cadastro do eleitor para ser voluntário na campanha nas ruas, indo além do ativismo online ${ }^{9}$. A campanha também se mostra atenta à importância das redes sociais e oferece a possibilidade de o eleitor personalizar o avatar com o botton do candidato.

Embora Tasso e Eunício estivessem aliados, é curioso perceber as diferenças entre as prioridades de cada um dos sites, o que indica distintas estratégias de comunicação entre as duas campanhas. O foco do site de Eunício é oferecer informações e mobilizar o eleitor,

\footnotetext{
${ }^{9} \mathrm{Na}$ visita no dia 2 de outubro, não era mais possível cadastrar-se como voluntário na página de Tasso. A opção para isto foi retirada.
} 
enquanto o candidato ao Senado se preocupa também em oferecer ferramentas de participação, sem deixar de lado a mobilização. É curioso que isso tenha acontecido em um momento no qual Tasso dominava as pesquisas de intenção de voto no Ceará, mas tinha dificuldade de se conquistar o eleitorado mais jovem ${ }^{10}$. A opção por oferecer maiores possibilidades de participação pode ser, em certa medida, uma tentativa de aproximar-se deste público.

O site de Mauro, por sua vez, assemelha-se bastante ao de Camilo - candidato a Governador pela sua coligação - tanto visualmente quanto no tipo de ferramenta enfatizada. O fato de os dois serem candidatos relativamente desconhecidos pode explicar a prioridade dedicada a fornecer informações. Porém, ambos fazem uma apropriação relativamente tímida das ferramentas de mobilização, não abrindo espaço para que o eleitor envie vídeos, fotos e mensagens de apoio à campanha, algo presente nas páginas de Eliane e de Eunício. O mais curioso, no entanto, é o fato de ambos não se utilizarem de ferramentas para promover participação dos cidadãos nos sites. A estratégia de comunicação, no caso de Mauro e de Camilo, parece ter sido pensada em conjunto e dedicou-se a procurar informar e mobilizar os eleitores em vez de fomentar a participação deles.

Não é razoável analisar os padrões de uso de ferramentas digitais de comunicação sem levar em conta o contexto no qual os candidatos estão inseridos. Assim como influi na mera adoção ou não de tais mecanismos (MARQUES; MONT'ALVERNE, 2013), também pode ajudar a explicar os motivos para que eles sejam utilizados de determinada forma. $\mathrm{O}$ fato de somente uma das candidaturas pedir doações à campanha, por exemplo, pode ter ligação com a cultura política brasileira, na qual não é comum este tipo de manifestação.

A ênfase em determinados mecanismos indica que tipo de estratégia de comunicação a campanha adotou. O trabalho procura não cair na armadilha mencionada por Nitschke et al. (2014) sobre questionar se a internet estaria sendo usada em seu total potencial, já que isso só levaria a diagnosticar déficits. No entanto, é necessário saber em que medida - e com quais objetivos - as ferramentas digitais têm sido utilizadas nas campanhas. A ausência ou presença de determinada ferramenta não acontece por acaso nem pode ser explicada, por completo, por limitações técnicas.

${ }^{10}$ Disponível em <http://www.opovo.com.br/app/opovo/politica/2014/08/16/noticiasjornalpolitica,3299220/tasso-lideracom-53-mauro-tem-18.shtml>. Acesso em 21 ago. 2014. 
Ainda que as dificuldades para construção de sites com oferta de ferramentas de participação devam ser consideradas (MARQUES, 2010), a questão parece ser de disposição dos agentes políticos em se abrirem a questionamentos, principalmente, quando se leva em conta a quantidade de recursos financeiros dos quais muitos dos candidatos dispõem ${ }^{11}$.

\begin{abstract}
Em vez de adotar todas as ferramentas disponíveis, os candidatos constroem suas campanhas online seletivamente, investindo em alguns recursos e evitando outros, baseados em cálculos de estratégia bem como preferências individuais e coletivas (i.e. relacionadas ao partido) e estilos de campanha (VACCARI, 2013, p. 33).
\end{abstract}

A predominância de ferramentas de Informação nos sites dos candidatos vai ao encontro dos resultados da pesquisa de Strommer-Galley (2013) sobre sites de candidatos dos Estados Unidos. Neles, também havia preponderância de material informativo. Gibson et al. (2003) obtiveram achados similares em relação a sites de candidatos a Presidente nos EUA e de partidos no Reino Unido, com foco em fornecer informações ao cidadão.

A repetição dos resultados indica que a resistência em abrir os sites a uma participação mais efetiva com o usuário não é um quadro exclusivo dos candidatos analisados. Auty e Cowen (2001, p. 347), inclusive, afirmam que o uso da internet pelos partidos políticos se dá como uma forma de "disseminar mensagens de modo top-down ou para arrecadar apoio ou dinheiro".

Isto acontece na medida em que abrir-se à interação mais efetiva com o usuário significa maiores riscos de perder o controle sobre eles, fazendo com que as campanhas deem preferência a ferramentas mais limitadas.

\footnotetext{
A função principal dos websites das campanhas é o provimento de informação controlada, cuidadosamente confeccionada. Similar aos panfletos impressos de campanha ou propagandas televisivas. Um segundo modo de uso é mais original: promover uma façanha de interação através da interação mediática. Esses componentes têm sido desenvolvidos e utilizados em websites de campanha por conta do baixo risco que acarretam e dos benefícios que parecem trazer (STROMMER-GALLEY, 2013, p. 47).
}

As próprias informações oferecidas, por sua vez, têm relação com o contexto político. Exemplo disso é o fato de os candidatos não ofertarem informações sobre os partidos. A campanha centra-se na figura do candidato e em sua biografia, não nos elementos partidários. Este tipo de utilização dos websites também foi diagnosticado por Gibson et al. (2003, p. 61). "Os sites dos candidatos à Presidência dos EUA (...) foram, não

\footnotetext{
${ }^{11}$ Disponível em http://bit.ly/1srxQuv. Acesso em 22 ago. 14.
} 
surpreendentemente, usados como ferramenta de promoção pessoal para ganhar suporte para o indivíduo, não para o partido como um todo".

Devem ser vistos com cautela, porém, as semelhanças encontradas com resultados de pesquisas realizadas em outros países, pelas diferenças no sistema político e no contexto eleitoral. A necessidade de alcançar uma quantidade maior ou menor de eleitores de acordo com o cargo pleiteado pode alterar a utilização das ferramentas digitais e a preponderância conferida a elas, como demonstram os trabalhos publicados no livro organizado por Aldé e Marques (2015).

Porém, as problemáticas que se apresentam sobre a interface entre o campo da política e a cultura mediática nos EUA, aproximam-se dos dilemas e das preocupações da realidade brasileira (AGGIO, 2010). Um exemplo é a preocupação acerca do tempo e espaço dos quais partidos e candidatos dispõem nos media, presente tanto nos Estados Unidos quanto no Brasil. Temáticas como participação política da sociedade, aproximação entre candidatos e eleitores, engajamento, informação política e mobilização são também análogas nas duas nações. Logo, contribuições do contexto americano são valorosas para o contexto do Brasil.

O pouco aparecimento do partido revela o que Afonso Albuquerque e Márcia Ribeiro Dias (2002) nomeiam como traço "personalista" da política brasileira, caracterizando-se pela fragilidade da figura partidária perante a imagem pessoal dos candidatos no momento da decisão do voto, como as campanhas eleitorais da maioria dos partidos políticos são centradas fundamentalmente na imagem do candidato.

Deve ser levada em conta, ainda, a possibilidade de que os candidatos adotem uma abordagem mais interativa nas redes sociais. O contexto faz com que algumas ferramentas sejam consideradas mais apropriadas que outras (ŠTĚTKA et al., 2014; MARQUES; MONT'ALVERNE, 2013; 2014), inclusive com finalidades diferentes. Nitschke et al. (2014) identificam que, em um mesmo partido, a ênfase de uso do Facebook e dos websites são diferentes. Questiona-se, porém, se é possível esperar maior abertura aos cidadãos em outros ambientes. Se, mesmo quando a página é configurada pela campanha, não são priorizados os mecanismos de participação ou de transparência, é provável que não haja grande preocupação em adotar este tipo de aproximação.

Como os websites pessoais são produções das próprias assessorias de campanha, os candidatos (e suas equipes) têm um maior controle sobre que tipos de recursos eles vão estar 
dispostos a disponibilizar e quais vão ser postos em prática. Existe uma pressão sobre ferramentas mais básicas como e-mail, agenda do candidato e biografia (MARQUES et al., 2013). Porém, diferentemente das redes sociais, os candidatos estão bem menos suscetíveis a se deparar com uma exposição negativa de sua própria imagem, pois podem escolher que tipo de conteúdo será abordado nas suas respectivas páginas. Além disso, websites são mais fáceis de serem moderados que comentários em redes sociais digitais como Facebook e Twitter.

\section{CONSIDERAÇÕES FINAIS}

A análise da ênfase dos websites dos candidatos a Governador e a Senador pelo Ceará, em 2014, aponta para um caráter fortemente informativo das páginas. Utilizando as categorias desenvolvidas por Schweitzer (2005; 2011), os eixos de interação e de mobilização também recebem certa atenção por parte de alguns agentes políticos. É notável, no entanto, a apropriação incipiente das ferramentas de participação.

Se estão preocupados em estarem presentes na internet, os candidatos não oferecem mecanismos realmente novos de participação ou de mobilização. O plano de governo - ou as propostas, no caso dos postulantes ao Senado - nem aparece em debate. O tipo de informações oferecidas tem um caráter específico. Não há dados sobre os partidos aos quais os agentes políticos pertencem. A transparência em relação ao financiamento de campanha também não é frequente, embora seja importante a divulgação da arrecadação por parte da campanha de Ailton Lopes, na medida em que pode forçar outros candidatos a fazer o mesmo.

Se não é o "elixir mágico" (STROMMER-GALLEY, 2013) para a resolução dos déficits democráticos, a internet pode colaborar para atenuá-los. O processo de abertura dos agentes políticos não acontece por si só, tendo as cobranças dos usuários papel importante nele. Daí a importância de um candidato adotar um conjunto de ferramentas diferenciadas, o que pode constranger os outros a também fazê-lo.

A partir da análise dos sites, é possível perceber que a ideia de equalização não se confirma, já que, apesar de a maioria dos candidatos possuir um website funcional, ainda não é possível afirmar que há uma equalização da comunicação política online. Alguns dos sites 
analisados são mais elaborados que outros e dispõem de mais ferramentas e recursos para a manutenção da página.

Já a ideia de normalização parece fazer mais sentido, mas também não explica a complexidade do processo de adoção de ferramentas online por agentes políticos. Um exemplo é o caso das candidatas do PSB: atuando no mesmo partido, Eliane e Geovana encontravam-se em situações bem distintas quanto às suas páginas na Web. Enquanto a campanha de Eliane parecia estar preocupada com a comunicação online da candidata, a de Geovana passou toda a campanha apenas com o domínio da página, sem fazer uso dele.

Mauro Filho, por sua vez, manteve uma página semelhante à de Camilo Santana, enquanto o site de Tasso se diferenciou da página de todos os candidatos, com diversas possibilidades de participação. No caso dos candidatos ao Governo, a ênfase das páginas deles era semelhante, apesar das diferenças entre os postulantes. Isto indica que a forma de utilizar o site depende das estratégias de comunicação traçadas pela campanha, levando em conta os cálculos de custo-benefício que cada ferramenta pode oferecer, sem comprovar a relação entre os recursos disponíveis às campanhas e aos partidos e a qualidade dos websites.

Vale ressaltar que não se pretende aqui sugerir que essa amostra seja representativa de tendências inequívocas e generalizantes. Além do mais, só dois candidatos a parlamentares estão sendo analisados nesta pesquisa. Este estudo tem limitações. Seria útil para pesquisas futuras incluir um maior número de estudos de caso, de modo que nos permita melhor isolar e testar as diferentes variáveis em jogo. Entrar em contato com os candidatos e com suas equipes de campanha também pode esclarecer a forma de utilização dos media digitais.

A diversidade de ferramentas que podem ser adotadas permite às campanhas escolher quais serão utilizadas. Mecanismos com o mesmo caráter podem ter finalidades diferentes. Uma grande oferta de ferramentas de participação não significa, necessariamente, abertura para contribuição dos cidadãos às propostas dos candidatos. Assim, a disposição dos agentes políticos e de suas assessorias se torna fundamental na definição dos limites para a interação com os usuários, a fim de oferecer possibilidades de participação e de transparência que vão além de enviar mensagens de apoio ou saber a biografia do candidato. 


\section{REFERÊNCIAS}

AGGIO, C. As campanhas políticas no Twitter: uma análise do padrão de comunicação política dos três principais candidatos à presidência do Brasil em 2010. IV Encontro da Associação Brasileira dos Pesquisadores em Política, Rio de Janeiro, RJ, abril, 2011.

AGGIO, C. Campanhas on-line: o percurso de formação das questões, problemas e configurações a partir da literatura produzida entre 1992 e 2009. In: ; MARQUES, F. P. J. A.; SAMPAIO, R. (Org.) Do clique à urna: internet, redes sociais e eleições no Brasil. Salvador: EDUFBA, 2013. p. 103-121.

ALBUQUERQUE, A.; DIAS, M. R. Propaganda política e a construção da imagem partidária no Brasil. Civitas, Porto Alegre, v.2, nº 2, dez. 2002.

ALDÉ, A.; MARQUES, F. P. J. Internet e poder local. Salvador: Edufba, 2015.

AUTY, C.; COWEN, A. Political parties on the Net -4 years closer to cyber-utopia? Aslib Proceedings, 2001.

BLUMLER, J. The Fourth Age of Political Communication. Disponível em <http://bit.ly/1oj4SJd >. Acesso em 23 ago. 14.

BRAGA, S. S. et al. Os partidos políticos brasileiros e a internet: uma avaliação dos websites dos partidos políticos do Brasil. Revista Sociologia e Política, v.17, n 34, p. 183-208, 2009.

et al. Elites políticas e novas tecnologias: uma análise do uso da pelos candidatos aos governos estaduais e ao senado nas eleições brasileiras de outubro de 2010. In: AGGIO, C.; MARQUES, F. P. J. A.; SAMPAIO, R. (Org.). Do clique à urna: internet, redes sociais e eleições no Brasil. Salvador: EDUFBA, 2013. p. 211-224.

CERVI, E; MASSUCHIN, M. G. HGPE e a formação da opinião pública no Brasil: análise das estratégias dos principais candidatos à presidência da república em 2010. Trabalho apresentado no Congresso Latino Americano de Opinião Pública - WAPOR, 2011.

DRUCKMAN, J. N.; KIFER, M. J.; PARKIN, M. The technological development of congressional candidate web sites. Social Science Computer Review, v. 25 , n ${ }^{\circ} 4$, p. $425-$ 442, 2007.

GIBSON, R.; WARD, S. A proposed methodology for studying the function and the effectiveness of party and candidate web sites. Social Science Computer Review, v. 18, $\mathrm{n}^{\circ}$ 3, p. 301-319, 2000.

et al. Election campaigning on the WWW in the USA and UK: A comparative analysis. PartyPolitics, v. 9, n 1, p. 47-75, 2003.

GOMES, W.; MAIA, R. C. M. Comunicação e democracia: problemas e perspectivas. São Paulo: Paulus, 2008. 
GULATI, G.; WILLIAMS, C. Closing the gap, raising the bar: candidate web site communication in the 2006 campaigns for Congress. Social Science Computer Review, v. 25, n 4, p. 443-465, 2007.

LILLEKER, D. et al. Political Parties and Web 2.0: The Liberal Democrat Perspective. Politics, v. 30, $\mathrm{n}^{\circ}$ 2, p. 105-112, 2010.

MAREEK, P. J. Campaign Communication \& Political Marketing. Wiley-Brackwell, 2011.

MARQUES, F. P. J. A. "Muro baixo, o povo pula": iniciativas institucionais de participação digital e seus desafios fundamentais. Opinião Pública, Campinas, v. 16, n¹, p. 117-142, 2010.

.; SAMPAIO, R. Internet e eleições 2010 no Brasil: rupturas e continuidades nos padrões mediáticos das campanhas online. Galáxia, São Paulo, nº 22, p. 208-221, 2011.

.; et al. Estratégias de Comunicação Política Online: Uma análise do perfil de José Serra no Twitter. In: MARQUES, F. P. J. A.; SAMPAIO, R.; AGGIO, C. (Org.). Do clique à urna: Internet, redes sociais e eleições no Brasil. Salvador: EDUFBA, p. 268-296, 2013.

.; MONT'ALVERNE, C. Twitter, eleições e poder local: Um estudo sobre os vereadores de Fortaleza. Contemporânea - Revista de Comunicação e Cultura, Salvador, v. $11, \mathrm{n}^{\circ} 2$, p. 322-347, 2013.

.; _. Mídias sociais e eleições: um estudo sobre as campanhas de reeleição dos vereadores de Fortaleza no Twitter. Fronteiras, São Leopoldo, v. 16, n 3, p. 228-242, 2014.

MARQUES, F. P. J. A.; SAMPAIO, R.; AGGIO, C. (Org.). Do clique à urna: internet, redes sociais e eleições no Brasil. Salvador: EDUFBA, 2013.

NITSCHKE, P. et al. Political organizations' use of websites and Facebook. New Media \& Society, p. 1-21, 2014.

RÖMMELE, A. Political Parties, party communication and new information and communication Technologies. Party Politics, v. 9, n 1, p. 7-20, 2003.

ROSSETTO, G.; CARREIRO, R.; ALMADA, M. P. Twitter e comunicação política: limites e possibilidades. In: Revista Compolítica, v. 3, n² 2, p. 190-216, 2013.

SANTOS, N. Modelos de Democracia e Soberania Popular: reflexão inicial sobre o papel dos sites de redes sociais. Revista Democracia Digital e Governo Eletrônico, n ${ }^{\circ}$ 6, p. 270-285, 2012.

SCHWEITZER, E. J. Election campaigning online: German party websites in the 2002 national elections. European Journal of Communication, v. 20, n 3, p. 327-351, 2005.

Normalization 2.0: a longitudinal analysis of German online campaigns in the national elections 2002-9. European Journal of Communication, v. 26, n 4, p. 310-327, 2011. 
ŠTĚTKA, V. et al. Professional Campaigning Online: the Role of New Media as Campaign Platforms. Disponível em: http://bit.ly/VJ0rR7. Acesso em: 22 ago. 2014.

STRANDBERG, K. Online Electoral Competition in Different Settings. A Comparative Meta-analysis of the Research on Party Websites and Online Electoral Competition. PartyPolitics, v. 14, n² 2 , p.223-244, 2008.

STROMER-GALLEY, J. Interação online e por que os candidatos a evitam. In: MARQUES, F. P. J. A.; SAMPAIO, R.; AGGIO, C. (Org.). Do clique à urna: internet, redes sociais e eleições no Brasil. Salvador: EDUFBA, 2013. p. 26-56

THOMPSON, J. B. A nova visibilidade. MATRIZES, V. 1, Nº 2, 2008.

VACCARI, C. A tale of two e-parties: Candidate websites in the 2008 US presidential primaries. Party Politics, v. 19, n 1, p. 19-40, 2013.

WILliAMS, A. P.; TRAMMELL, K. D. Candidate Campaign E-Mail Messages in the Presidential Election 2004. American Behavioral Scientist, v. 49, p. 560-574, 2005. 


\section{ANEXOS}

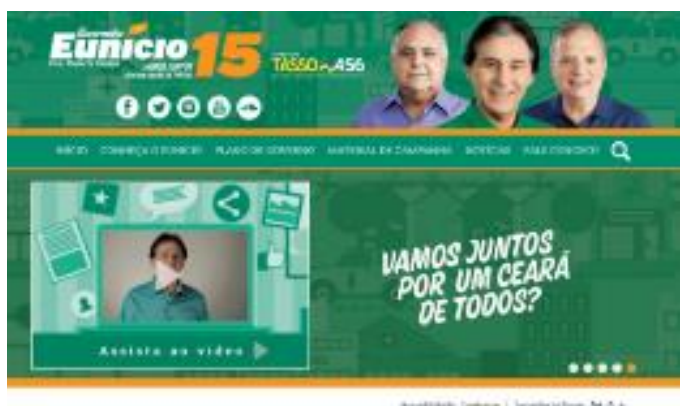

COMITÊ DIGTTAL IS
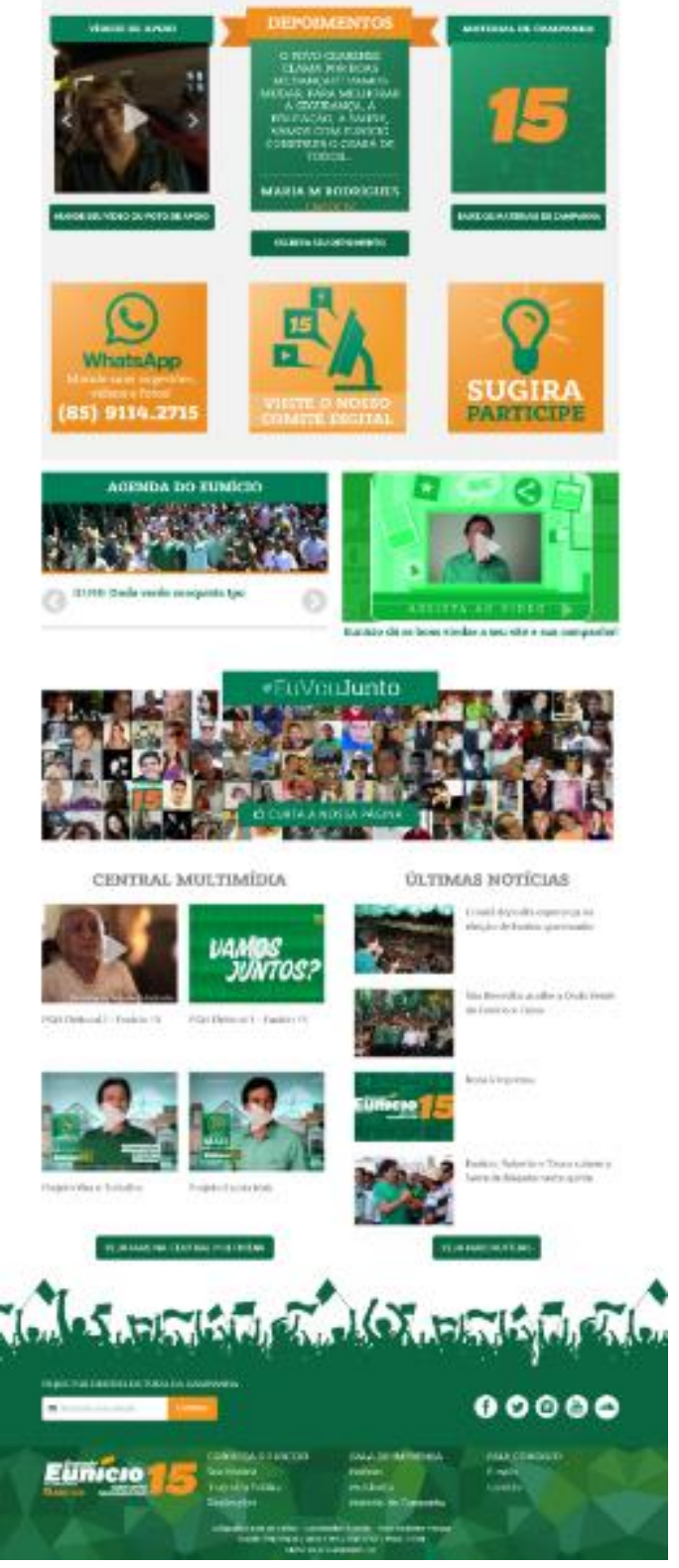

Figura 1Print-screen do site de Eunício Oliveira (PMDB) 


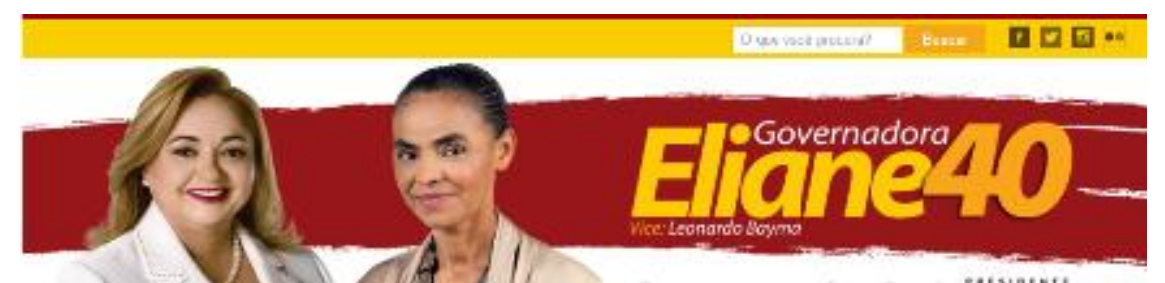

Coragempramudaro Ceará M̈ÁRINÁA4O
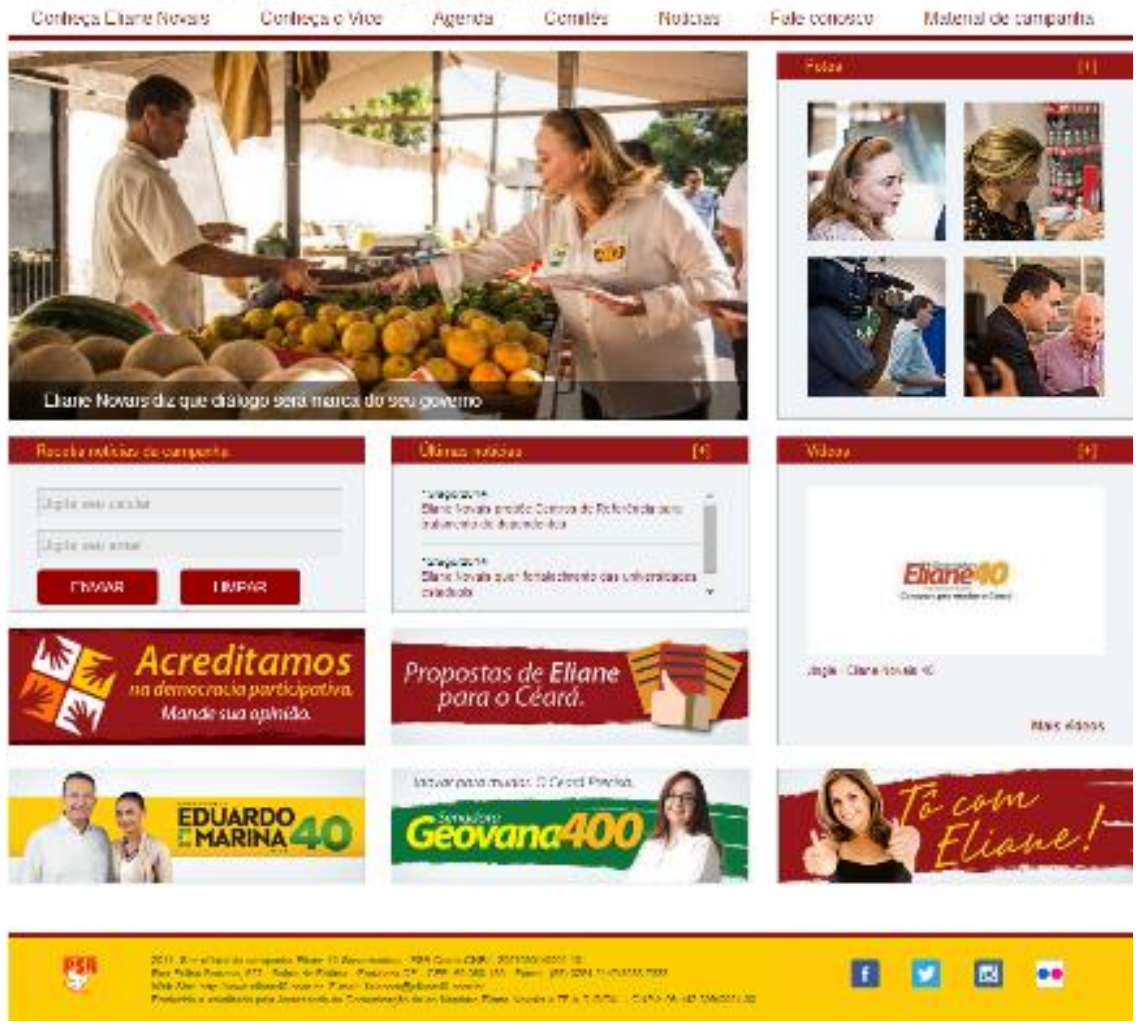

Figura 2 Print-screen do site de Eliane Novais (PSB) 

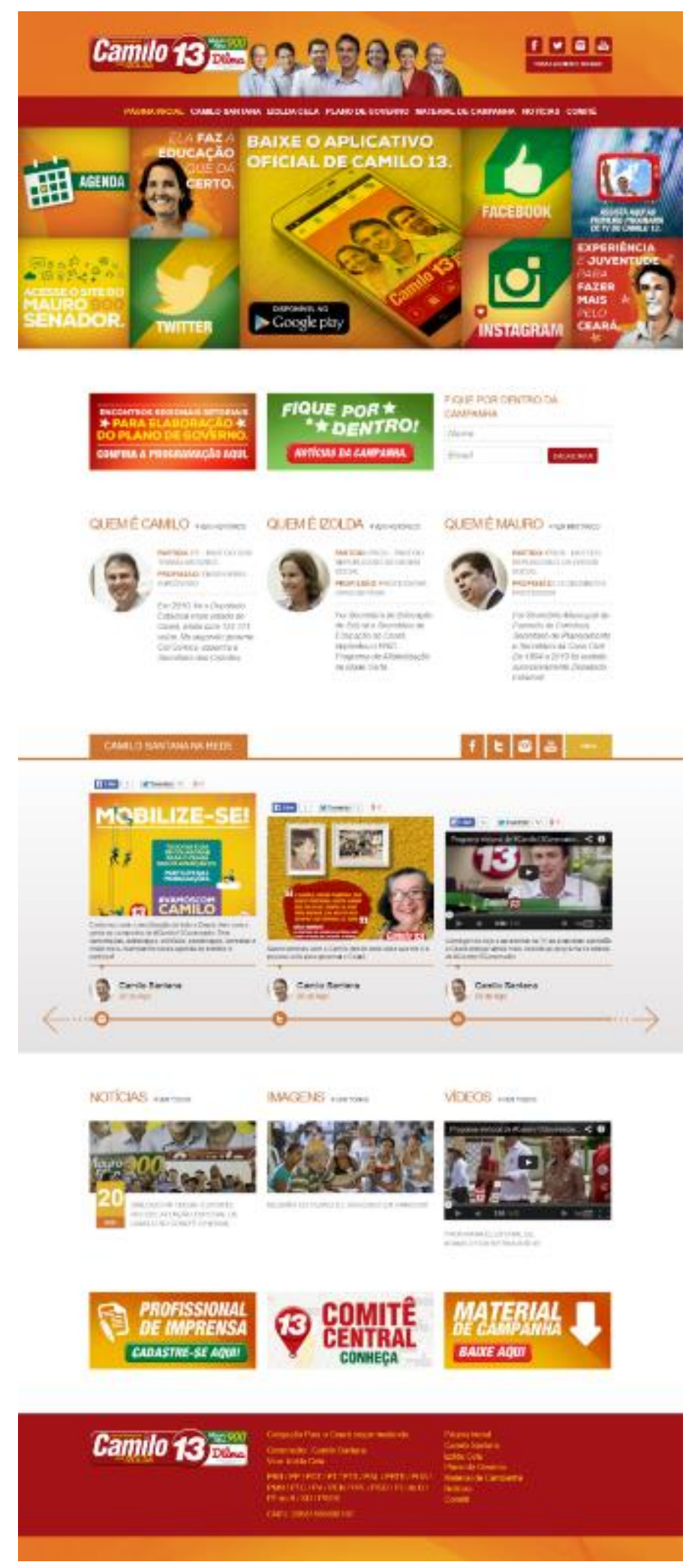

Figura 3 Print-screen do site de Camilo Santana (PT) 

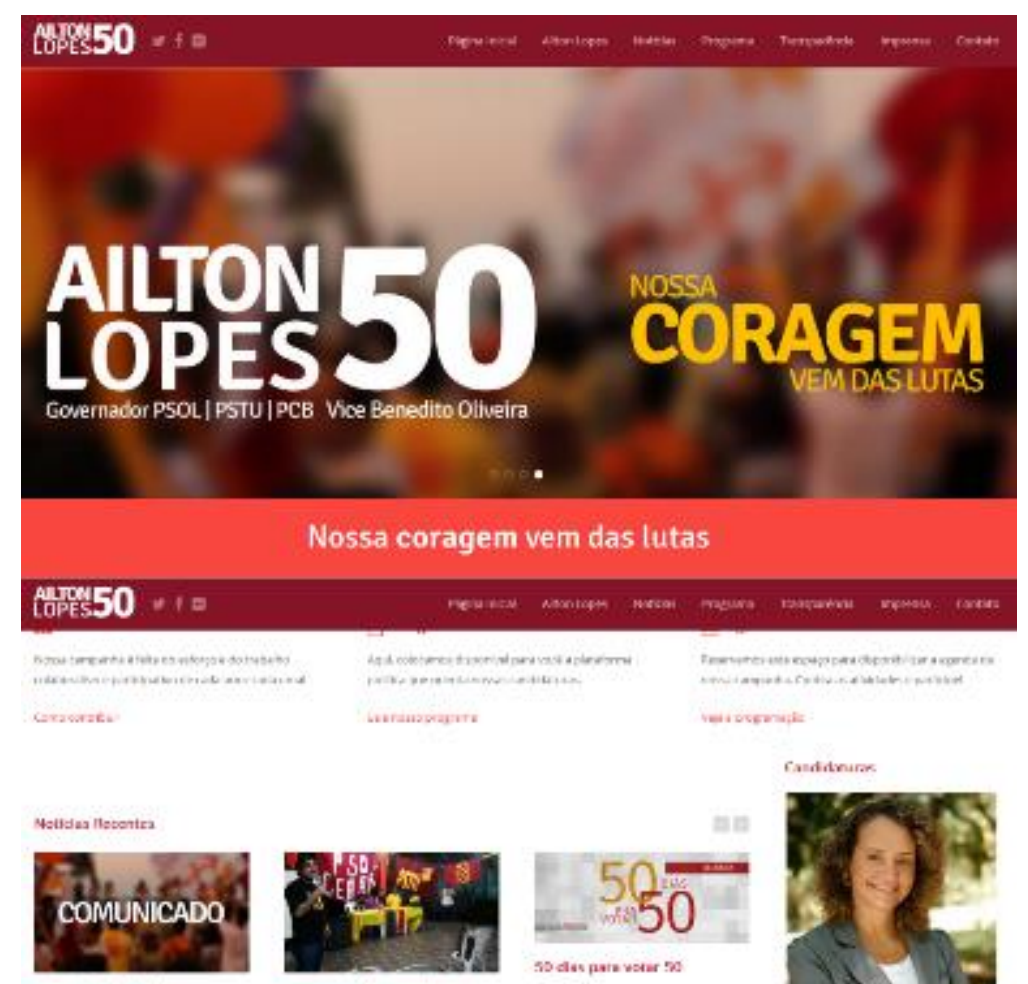

Desam an TV inian
cherfivo

sonive

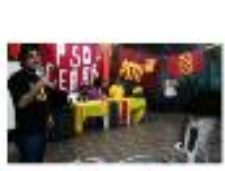

Nare emude as robion not

tersins
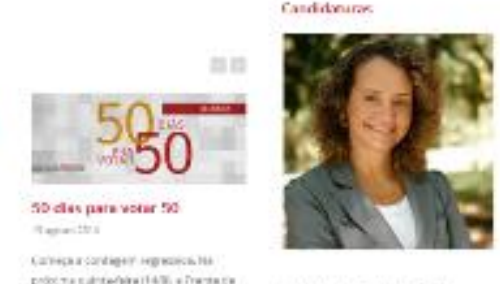

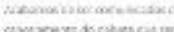

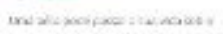

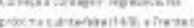

Leciana Gerwo, 50

Candides a providente asous

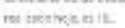

erewers.

swanes:
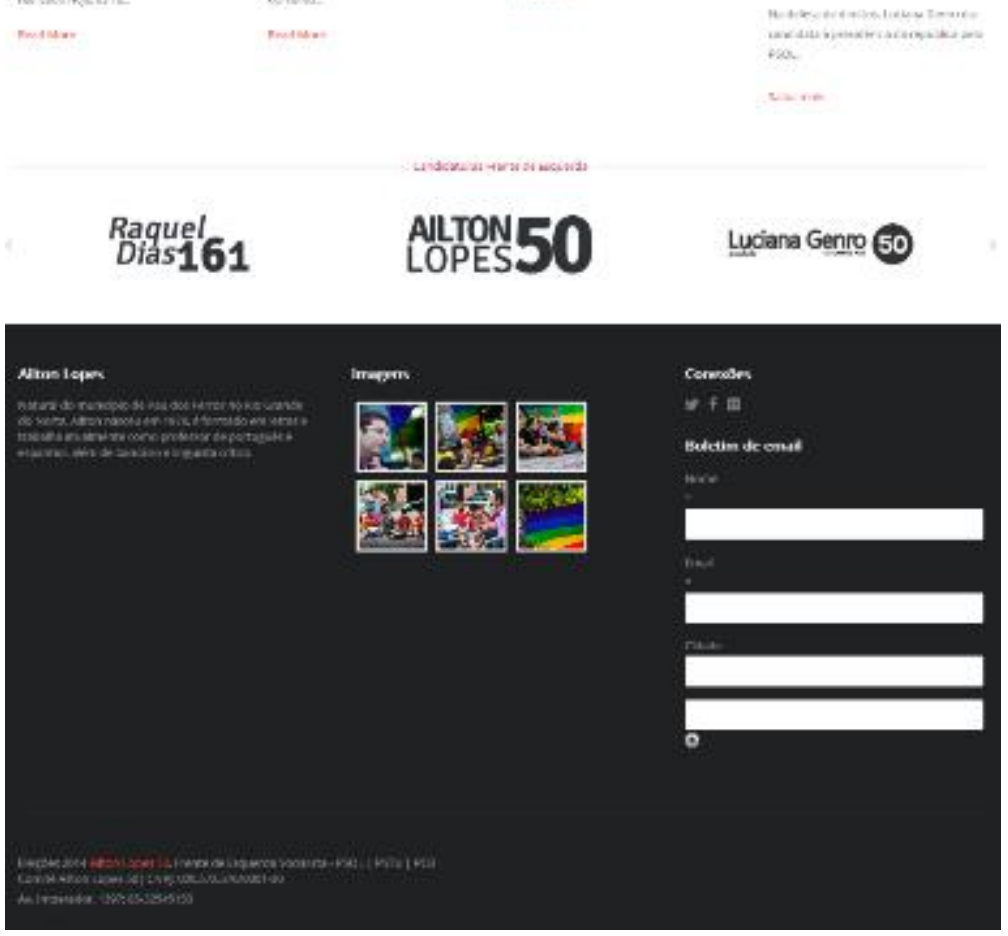

Figura 4 Print-screen do site de Ailton Lopes (PSOL) 


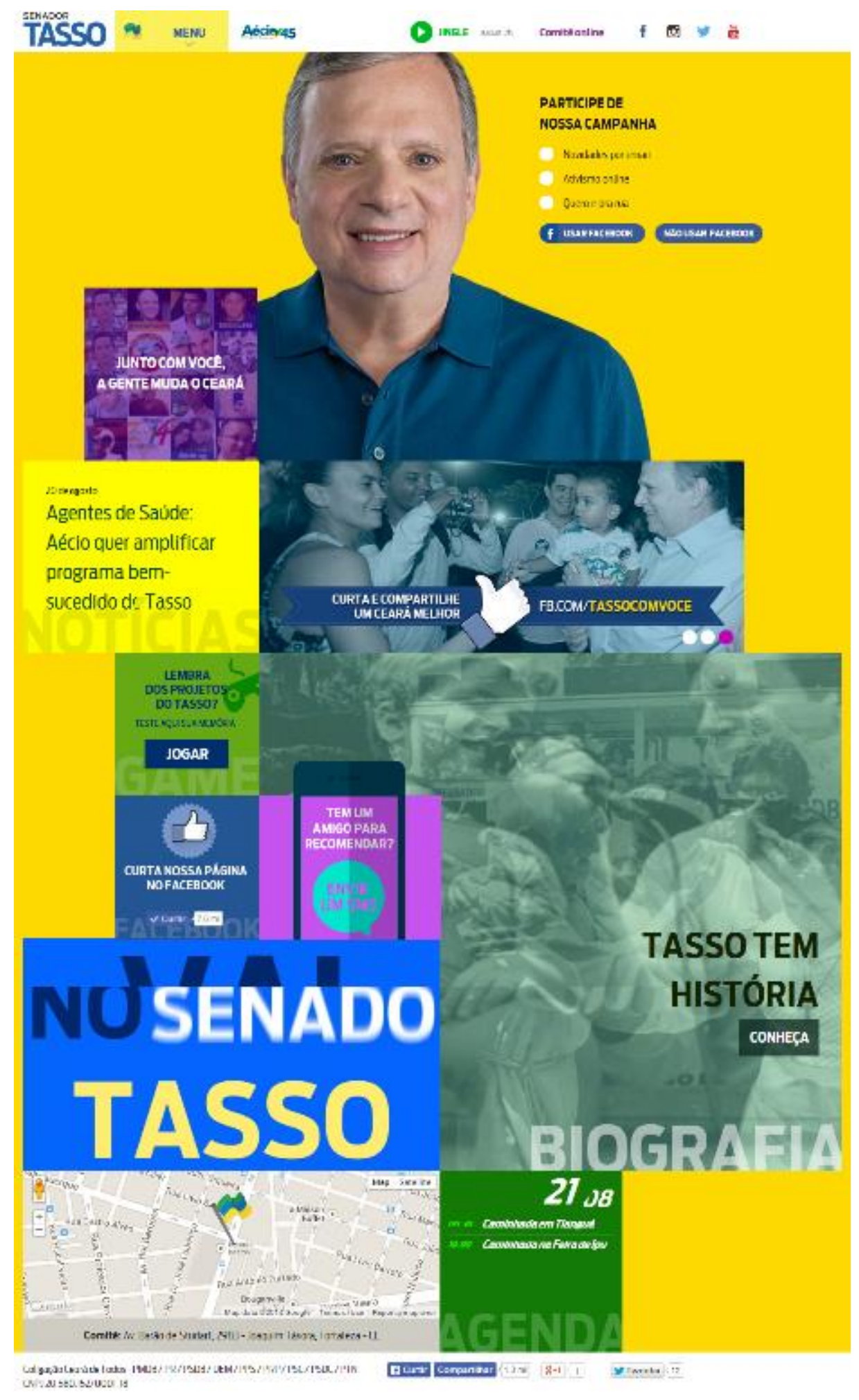

Figura 5 Print-screen do site de Tasso Jereissati (PSDB) 

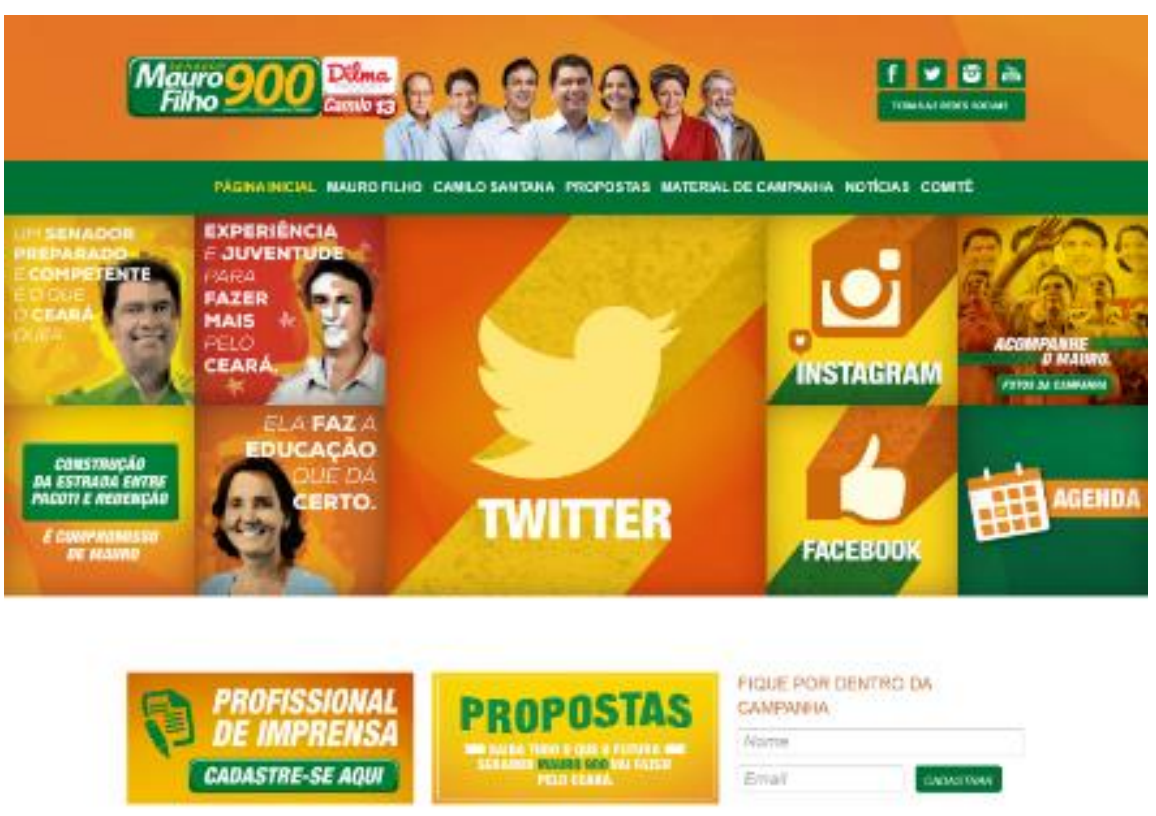

PLLE PON DENTRE DN

CANFyera
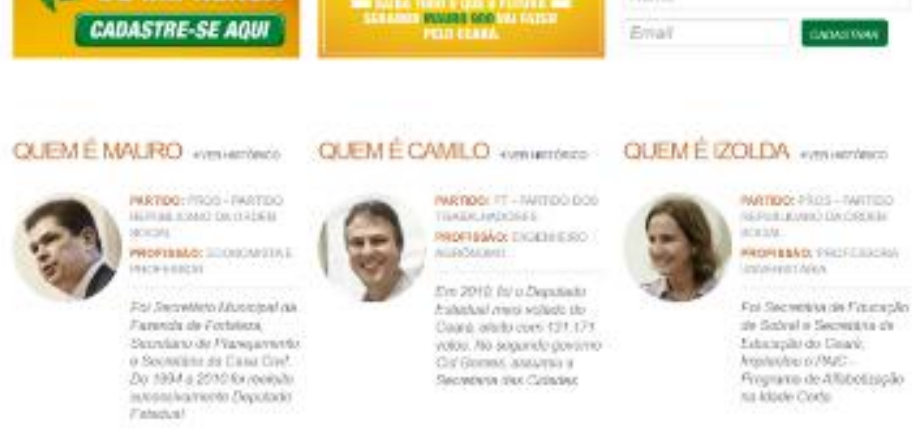

Notichs wanow

IMWAGENS namon

ViDEOS norrooes
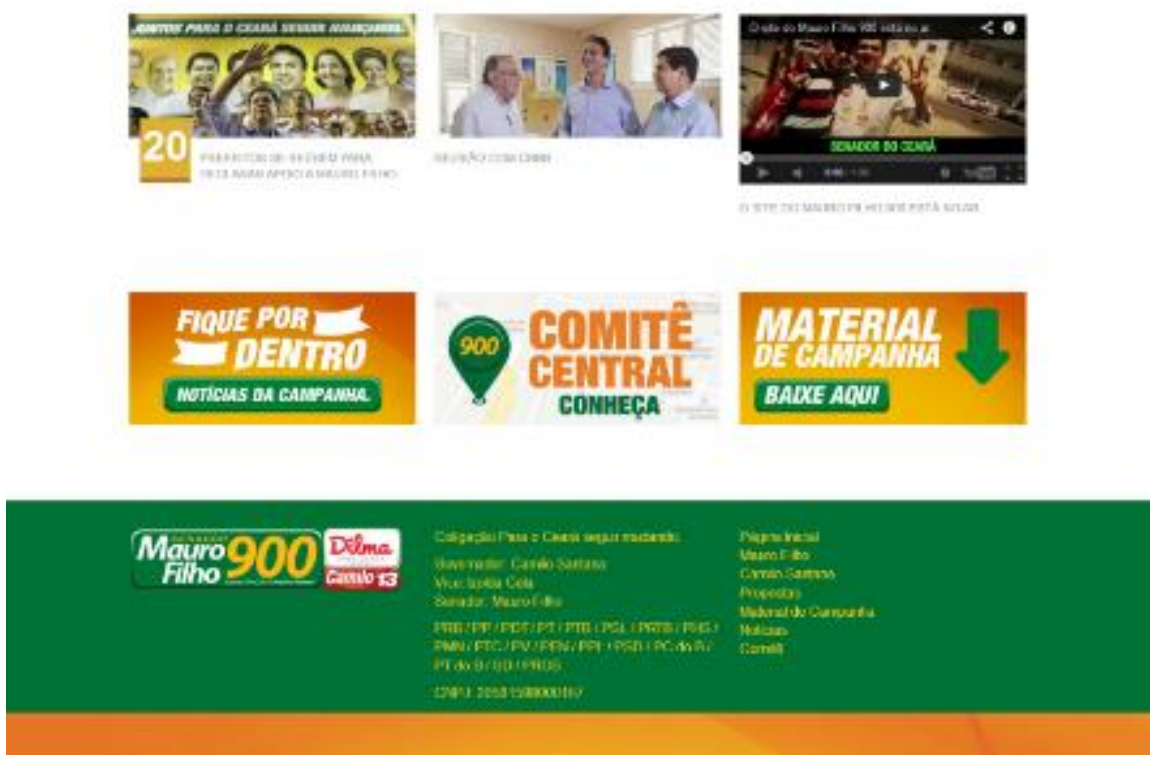

Figura 6 Print-screen do site de Mauro Filho (PROS) 